(1.) Us. ENERER

Prepared for the U.S. Department of Energy

under Contract DE-AC05-76RL01830

\title{
A General Investigation of Optimized Atmospheric Sample Duration
}

Paul W. Eslinger

Harry S. Miley

October 2012

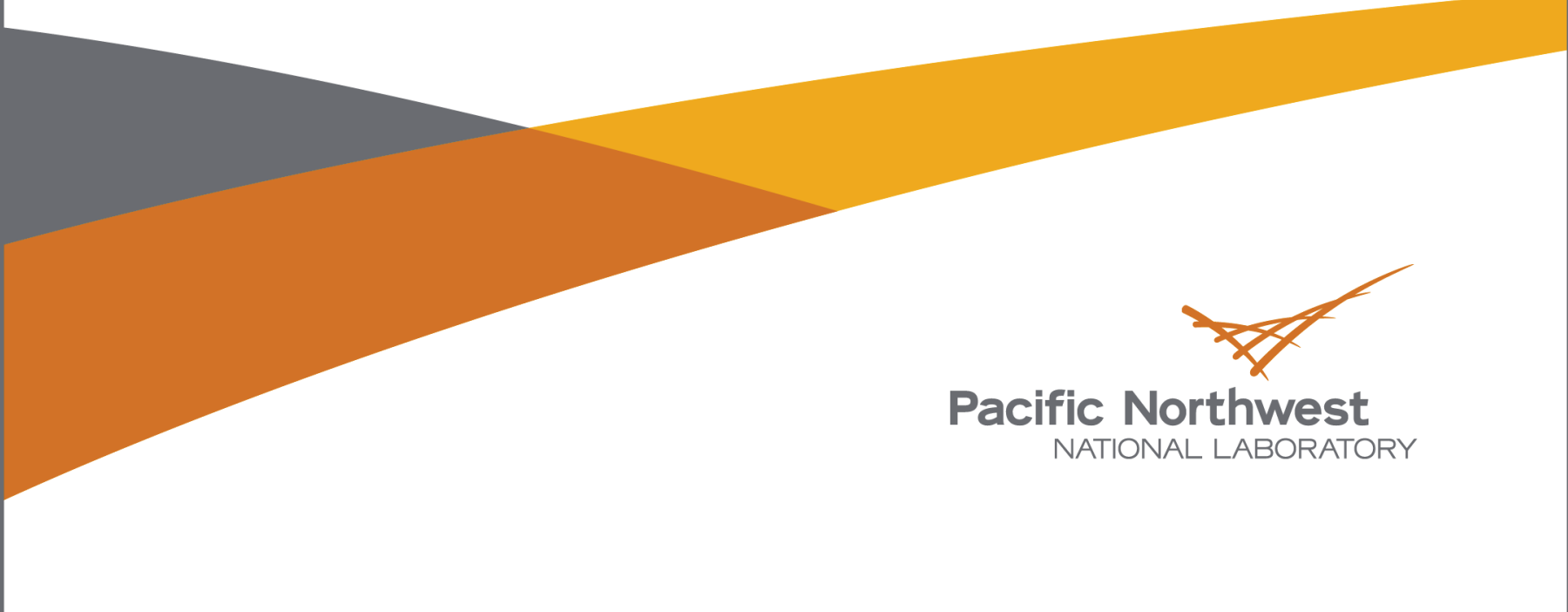




\title{
DISCLAIMER
}

This report was prepared as an account of work sponsored by an agency of the United States Government. Neither the United States Government nor any agency thereof, nor Battelle Memorial Institute, nor any of their employees, makes any warranty, express or implied, or assumes any legal liability or responsibility for the accuracy, completeness, or usefulness of any information, apparatus, product, or process disclosed, or represents that its use would not infringe privately owned rights. Reference herein to any specific commercial product, process, or service by trade name, trademark, manufacturer, or otherwise does not necessarily constitute or imply its endorsement, recommendation, or favoring by the United States Government or any agency thereof, or Battelle Memorial Institute. The views and opinions of authors expressed herein do not necessarily state or reflect those of the United States Government or any agency thereof.

\author{
PACIFIC NORTHWEST NATIONAL LABORATORY \\ operated by \\ BATTELLE \\ for the \\ UNITED STATES DEPARTMENT OF ENERGY \\ under Contract DE-AC05-76RL01830
}

Printed in the United States of America
Available to DOE and DOE contractors from the Office of Scientific and Technical Information,
P.O. Box 62, Oak Ridge, TN 37831-0062;
ph: (865) 576-8401
fax: $(865)$ 576-5728
email: reports@adonis.osti.gov

\begin{abstract}
Available to the public from the National Technical Information Service, U.S. Department of Commerce, 5285 Port Royal Rd., Springfield, VA 22161 ph: (800) 553-6847 fax: $(703) 605-6900$ email: orders@ntis.fedworld.gov online ordering: http://www.ntis.gov/ordering.htm
\end{abstract}

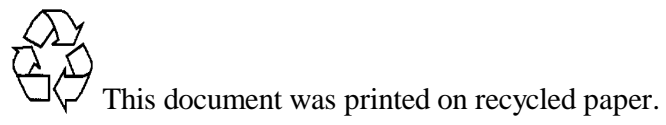


PNNL-21966

\section{A General Investigation of Optimized Atmospheric Sample Duration}

Paul W. Eslinger

Harry S. Miley

October 2012

Prepared for

the U.S. Department of Energy

under Contract DE-AC05-76RL01830

Pacific Northwest National Laboratory

Richland, Washington 99352 


\section{ABSTRACT}

The International Monitoring System (IMS) consists of up to 80 aerosol and xenon monitoring systems spaced around the world that have collection systems sensitive enough to detect nuclear releases from underground nuclear tests at great distances (CTBT 1996; CTBTO 2011). Although a few of the IMS radionuclide stations are closer together than $1,000 \mathrm{~km}$ (such as the stations in Kuwait and Iran), many of them are $2,000 \mathrm{~km}$ or more apart.

In the absence of a scientific basis for optimizing the duration of atmospheric sampling, historically scientists used a integration times from 24 hours to 14 days for radionuclides (Thomas et al. 1977). This was entirely adequate in the past because the sources of signals were far away and large, meaning that they were smeared over many days by the time they had travelled 10,000 km. The Fukushima event pointed out the unacceptable delay time ( 72 hours) between the start of sample acquisition and final data being shipped. A scientific basis for selecting a sample duration time is needed.

This report considers plume migration of a nondecaying tracer using archived atmospheric data for 2011 in the HYSPLIT (Draxler and Hess 1998; HYSPLIT 2011) transport model. We present two related results: the temporal duration of the majority of the plume as a function of distance and the behavior of the maximum plume concentration as a function of sample collection duration and distance. The modeled plume behavior can then be combined with external information about sampler design to optimize sample durations in a sampling network. 


\section{Contents}

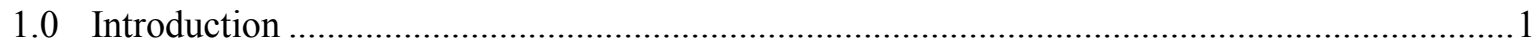

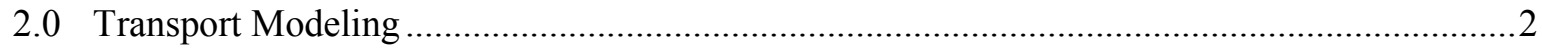

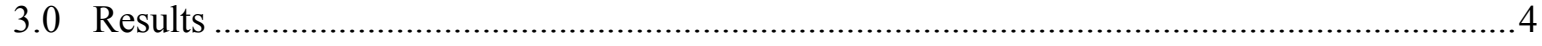

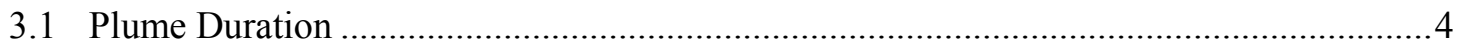

3.2 Uncertainty in Plume Concentrations ..................................................................... 7

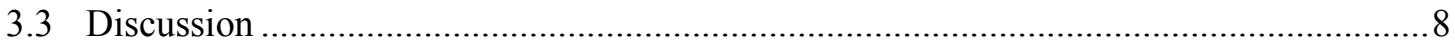

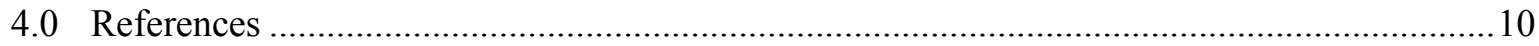

\section{Tables}

Table 2.1 Transport grid resolution and meteorological data for each modeling case. .2

\section{Figures}

Figure 2.1 Release point and sample locations for circles of $100 \mathrm{~km}$ or more in radius..................

Figure 3.1 Illustration of plume length metrics for a stylized plume concentration profile...............5

Figure 3.2 Number of hours that the plume concentrations at the point of maximum concentration are at or above $1 \%$ of the maximum concentration for different transport distances.

Figure 3.3 Number of hours that the plume concentrations at the point of maximum concentration are at or above $1 \%$ of the maximum concentration for different transport distances, using a limited time scale.

Figure 3.4 Number of hours that the plume concentrations at the point of maximum concentration are at or above $50 \%$ of the maximum concentration for different transport distances.

Figure 3.5 Example modeled plume time history at a distance of $250 \mathrm{~km}$ from the source. 7

Figure 3.6 Average maximum concentrations and $90 \%$ concentration ranges as a function of distance and number of hours in the sampling interval for a 1-hour release of $10^{12}$ mass units. 


\subsection{Introduction}

The International Monitoring System (IMS) consists of up to 80 aerosol and xenon monitoring systems spaced around the world that have collection systems sensitive enough to detect nuclear releases from underground nuclear tests at great distances (CTBT 1996; CTBTO 2011). Although a few of the IMS radionuclide stations are closer together than $1,000 \mathrm{~km}$ (such as the stations in Kuwait and Iran), many of them are 2,000 km or more apart. However, the stations can be much closer to radionuclide sources, like the Takasaki station at $250 \mathrm{~km}$ from the stricken Fukushima Daiichi nuclear plants, than the average distance.

Nuclear tests induce vibrations in the earth, and seismologists monitor vibrations for indications of a nuclear test among the many earthquakes that occur each day. This is made difficult by the unknown medium that transmits the vibrations. Geoscientists labor to calibrate the speed of sound in the transmission medium of their signals. The Earth's atmosphere similarly has only partially known transmission properties, but far worse, these properties change every hour of every day. In the absence of a scientific basis for optimizing the duration of atmospheric sampling, historically scientists used a integration times from 24 hours to 14 days for radionuclides (Thomas et al. 1977). This was entirely adequate in the past because the sources of signals were far away and large, meaning that they were smeared over many days by the time they had travelled 10,000 km. The Fukushima event pointed out the unacceptable delay time (72 hours) between the start of sample acquisition and final data being shipped.

A scientific basis for selecting a sample duration time is needed. We present a simple atmospheric transport modeling exercise using a hypothetical release of one hour in duration. The variations in concentration and plume duration are then examined as a function of distance. Multiple cases use archived meteorological data for an entire year. 


\subsection{Transport Modeling}

Atmospheric transport was modeled using the Hybrid Single Particle Lagrangian Integrated Trajectory (HYSPLIT) model, parallel version 4.9, maintained by the U.S. National Oceanographic and Atmospheric Administration (Draxler and Hess 1998; HYSPLIT 2011). The transport runs were performed on a 168 compute-node Linux cluster.

Model concentrations at sampling locations were averaged over the bottom 100 meters of the atmospheric column. The top of the 23-layer atmospheric model domain was set at 10,000 m above ground level. Wet and dry deposition mechanisms were deactivated for the runs and no radioactive decay was simulated. All of the transport runs output concentration data on a 1-hour time step. These hourly data were then post-processed to simulate aggregate concentrations for sample collection periods of different lengths.

The same source location was the same for all of the model cases. The source location was set at $42^{\circ} \mathrm{N}$ and $93^{\circ} \mathrm{W}$ in Wisconsin, USA. The location choice was arbitrary, but previous model runs performed for other purposes indicated that releases in this region had the potential to move thousands of $\mathrm{km}$. In order to account for regional and seasonal differences, 365 transport runs were made for each case. Each run used archived meteorological data and started on a different day in 2011. Accuracy requirements led to using different transport grid resolutions and meteorological data sets for different cases. The associated data are identified in Table 2.1. Each transport runs used a source release of $10^{12}$ mass units of a nondecaying, nondepositing tracer. Each plume is post-processed independently of the other plumes; that is, no plume superposition is performed.

Table 2.1 Transport grid resolution and meteorological data for each modeling case.

\begin{tabular}{|l|l|l|}
\hline $\begin{array}{l}\text { Modeling } \\
\text { Case }\end{array}$ & $\begin{array}{l}\text { Transport Grid Resolution } \\
\text { Latitude and Longitude }(d e g .)\end{array}$ & $\begin{array}{l}\text { Atmospheric } \\
\text { Data Set }\end{array}$ \\
\hline Fence $(1 \mathrm{~km})$ & 0.001 & edas $^{\mathrm{a}}$ \\
\hline Local $(50 \mathrm{~km})$ & 0.005 & edas $^{\mathrm{a}}$ \\
\hline Subregion $(100 \mathrm{~km})$ & 0.05 & edas $^{\mathrm{a}}$ \\
\hline Region $(250 \mathrm{~km})$ & 0.05 & edas $^{\mathrm{a}}$ \\
\hline State $(500 \mathrm{~km})$ & 0.1 & edas $^{\mathrm{a}}$ \\
\hline Country $(1000 \mathrm{~km})$ & 0.1 & edas $^{\mathrm{a}}$ \\
\hline Continent $(5000 \mathrm{~km})$ & 0.5 & gdas $^{\mathrm{b}}$ \\
\hline
\end{tabular}

a. edas: North American $40 \mathrm{~km}$ data set (EDAS 2012)

b. gdas: Global $110 \mathrm{~km}$ data set (GDAS 2012)

Concentrations for each case are examined at a specified distance from the source location. The distance was implemented by examining up to 1,000 locations equidistant from each other on a circle of the given radius. Post-processing of the results for each case was done for the single location on each circle that had the maximum concentration during the plume passage. The maximum concentration was used to select the location and then the time history of the plume at that location was used in the analysis. In 
essence, we assume there is a sampler in the correct location to measure the highest concentration in the plume, even though plumes can move in different directions on different days.

The release point and the sample locations for circles of $100 \mathrm{~km}$ or more in radius are provided in Figure 2.1. The map projection distorts the $5,000 \mathrm{~km}$ circle so it doesn't look like a circle. The measurement locations coincide with positions on the transport grid, and the grid resolution changes by case (see Table $2.1)$ so the measurement locations only approximate equidistant points.

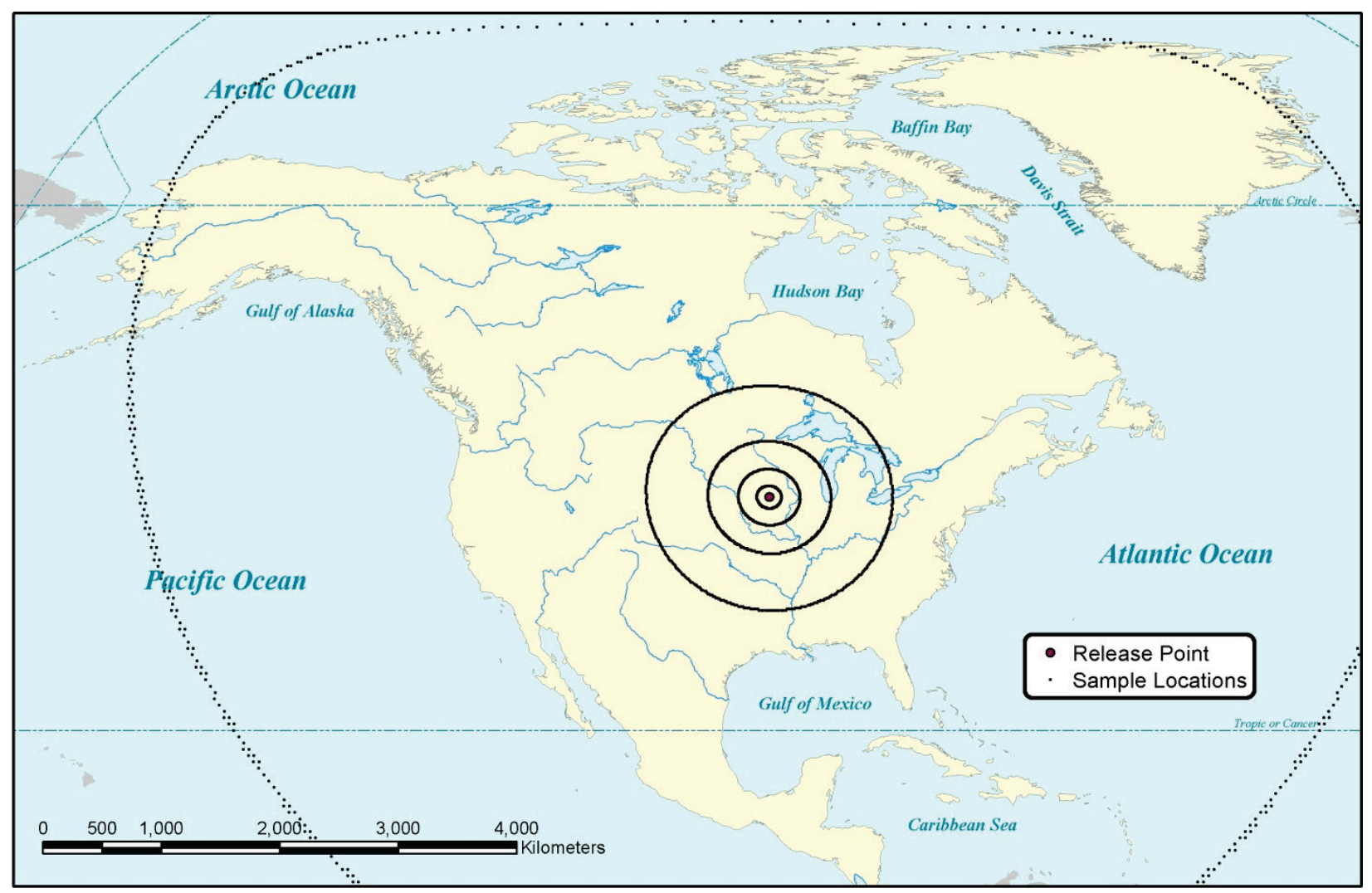

Figure 2.1 Release point and sample locations for circles of $100 \mathrm{~km}$ or more in radius. 


\subsection{Results}

We present two related results. The first result is the temporal duration of the majority of the plume as a function of distance from the release point. The second result is the average maximum plume concentration as a function of distance from the release point, along with the uncertainty or spread in the maximum concentrations.

\subsection{Plume Duration}

The length of time a plume persists at an individual location is an important consideration in optimizing the sample collection period. We use two simple metrics to indicate the length of time a plume persists at the location of maximum concentration.

- 1\% Concentration Duration: This metric is computed as the number of hours, using concentrations from the 1-hour output time periods from the transport model, where the modeled concentration is within $1 \%$ of the maximum concentration. Although these hours do not have to be contiguous in time for the calculation, they actually are contiguous in time for almost all of the runs.

- $\quad \mathbf{5 0} \%$ Concentration Duration: This metric is computed as the number of hours, using concentrations from the 1-hour output time periods from the transport model, where the modeled concentration is within $1 \%$ of the maximum concentration.

These two plume length metrics are illustrated in Figure 3.1 for a stylized concentration profile. For this stylized profile, about $75 \%$ of the mass in the plume passes that location in the time interval associated with the $50 \%$ concentration duration metric. About $99.6 \%$ of the mass in the plume passes that location in the time interval associated with the $1 \%$ concentration metric. Different time histories for an actual plume will modify these mass percentages, however, even the $50 \%$ concentration duration metric brackets the time interval where the majority of the mass in the plume passes the collection point.

The number of hours that the plume concentrations at the point of maximum concentration are at or above $1 \%$ of the maximum concentration for different transport distances is shown in Figure 3.2. The probability axis is based on a total of 365 transport runs for each distance.

The same results are shown in Figure 3.3 as in Figure 3.2 but the horizontal axis scale is limited to 24 hours. The results for the $5,000 \mathrm{~km}$ plumes look a little different than the other distances for short plume durations. This difference is due to the fact that a number of the plumes are just reaching this longer distance by the end of the transport run. The runs only simulated 2 weeks ( 336 hours) of transport.

As noted in Section 2.0, the releases were all one hour in length. Close to the release point $(1 \mathrm{~km})$, virtually all the plume has passed the measurement location within two hours. In about $90 \%$ of the runs, the highest portion of the plume passes the measurement location at $50 \mathrm{~km}$ in a three hour time period. At 100 kilometers, the time for the majority of the plume passage extends to 6 hours. At $250 \mathrm{~km}$, the plume duration moves to about 12 hours in $85 \%$ of the runs. 


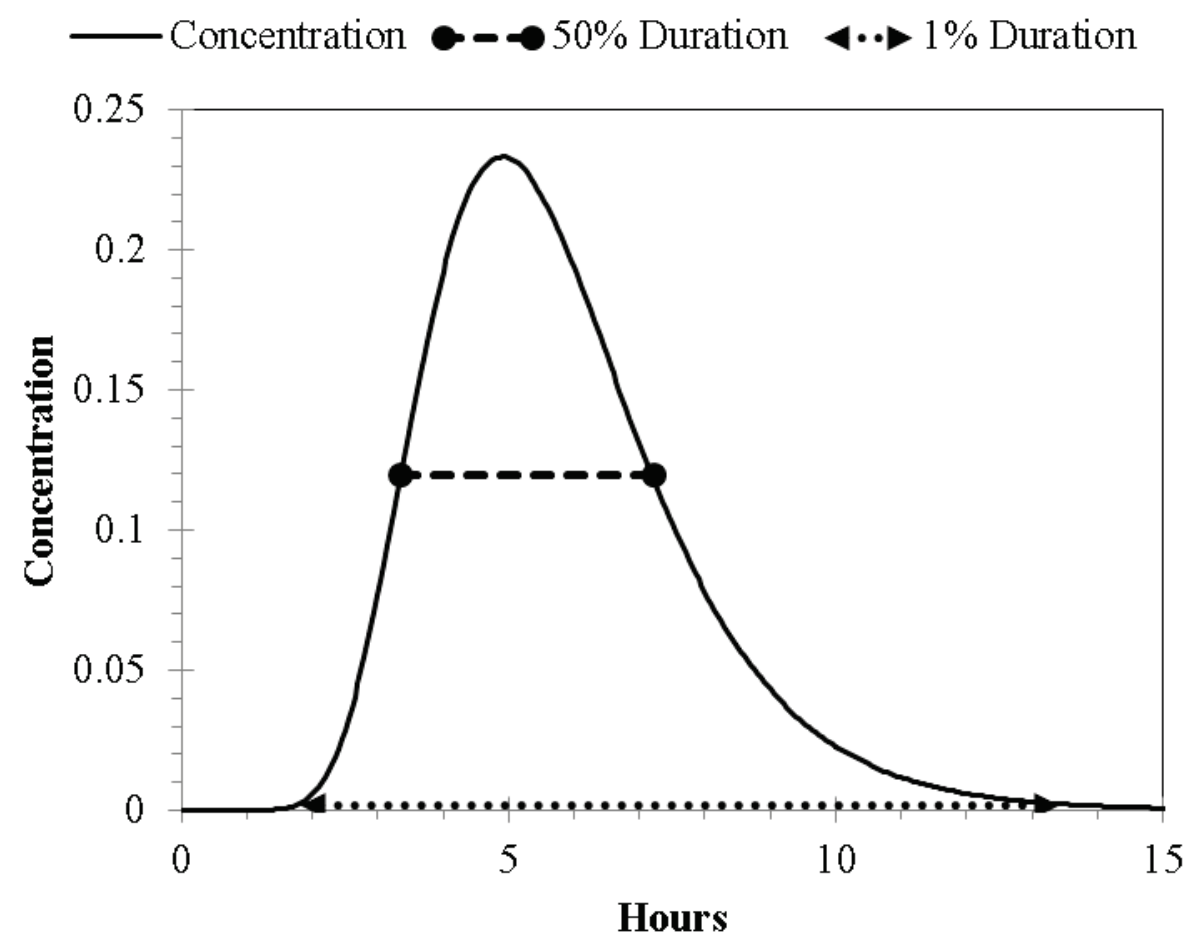

Figure 3.1 Illustration of plume length metrics for a stylized plume concentration profile.

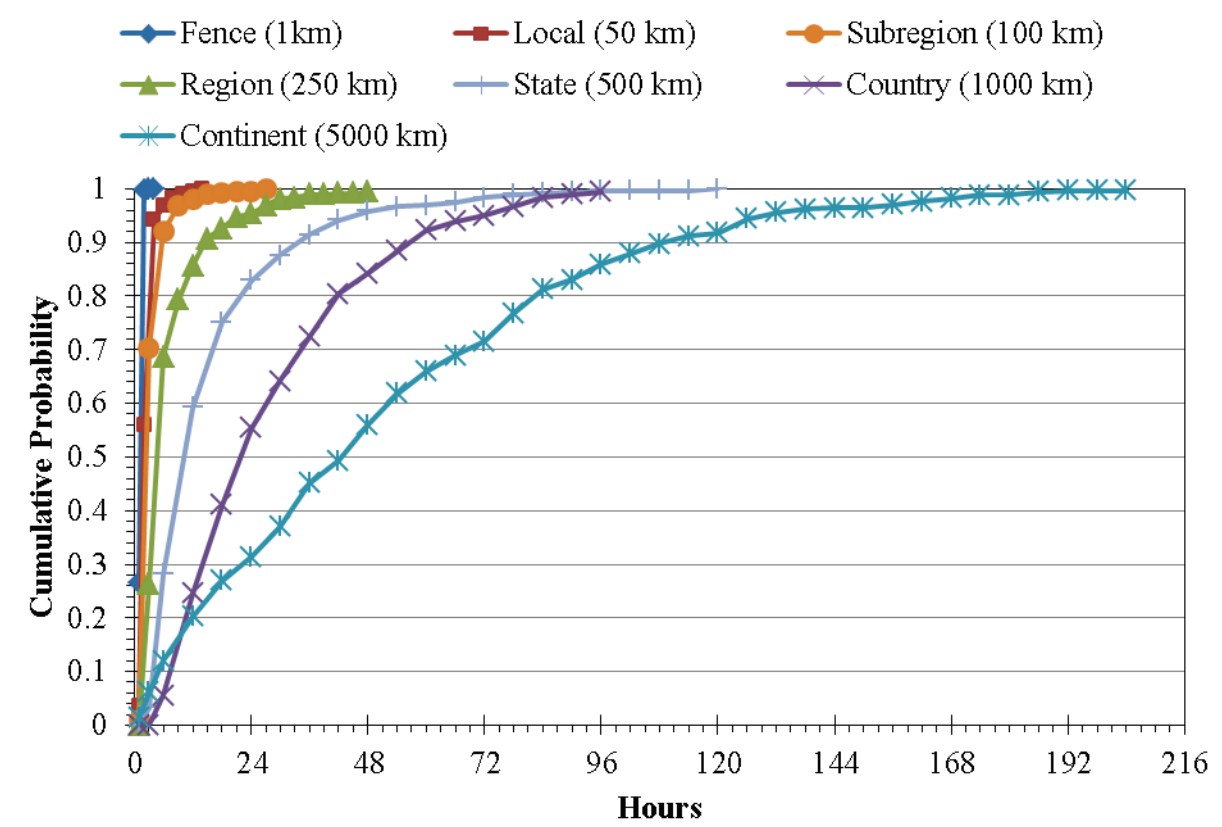

Figure 3.2 Number of hours that the plume concentrations at the point of maximum concentration are at or above $1 \%$ of the maximum concentration for different transport distances. 


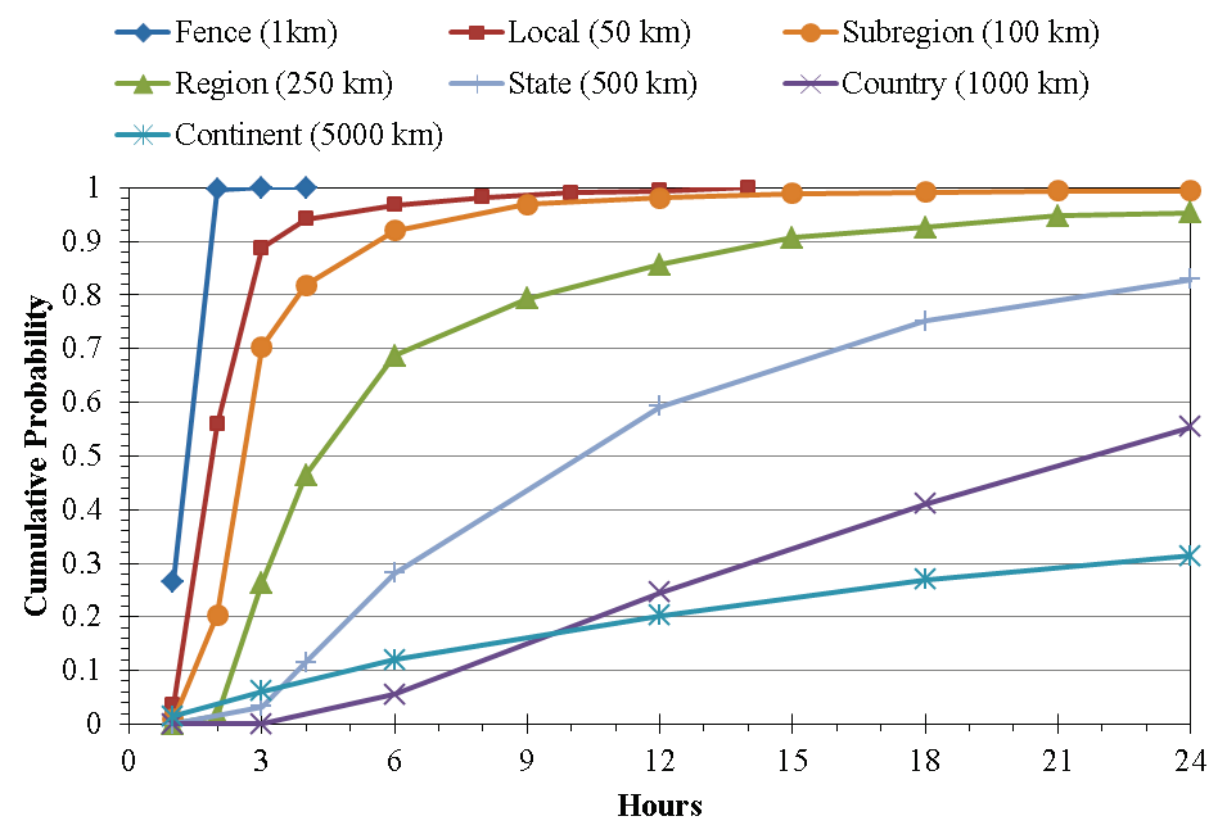

Figure 3.3 Number of hours that the plume concentrations at the point of maximum concentration are at or above $1 \%$ of the maximum concentration for different transport distances, using a limited time scale.

The plume durations by distance are shown in Figure 3.4 for the $50 \%$ concentration level metric. In this case, as expected, the plume durations are shorter than for the $1 \%$ concentration level metric.

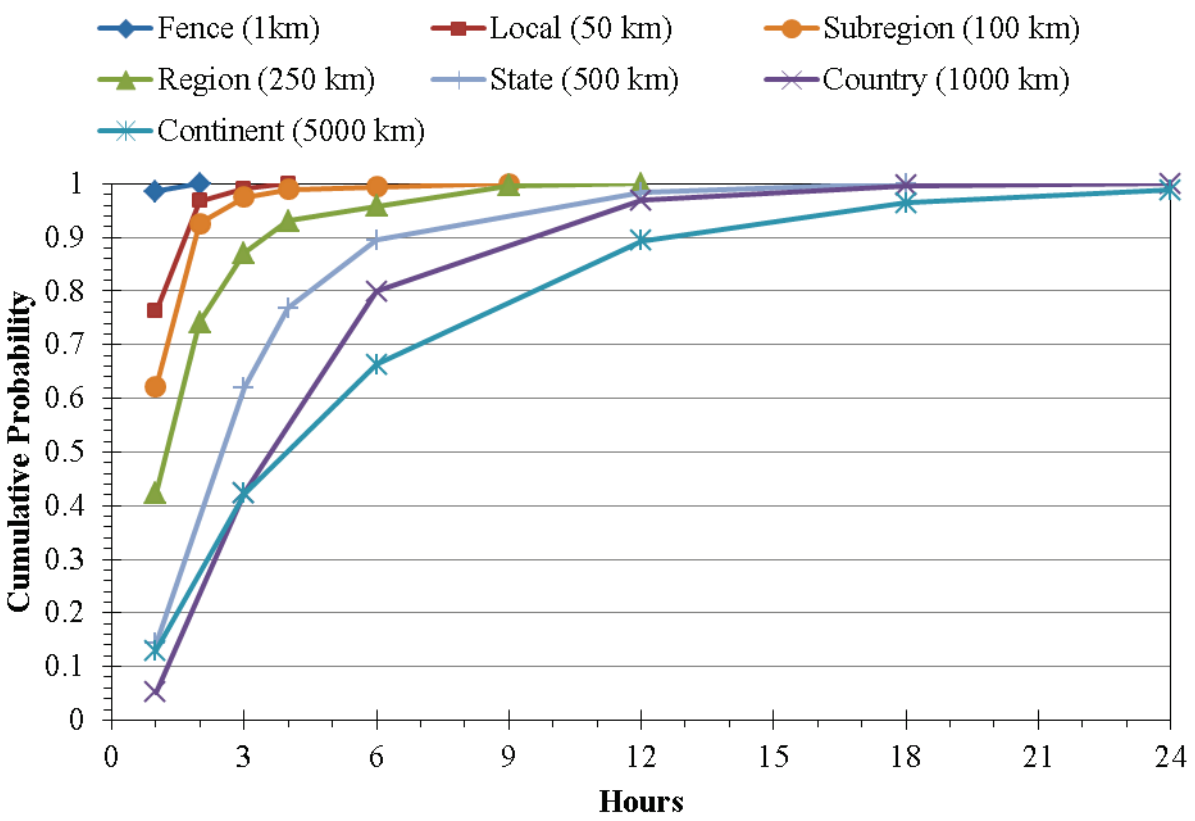

Figure 3.4 Number of hours that the plume concentrations at the point of maximum concentration are at or above $50 \%$ of the maximum concentration for different transport distances. 
Finally, we show an example modeled plume time history at a distance of $250 \mathrm{~km}$ from the source for the location where the maximum modeled concentration occurs. This particular plume has a length of 4 hours using the $50 \%$ concentration level metric and a length of 12 hours using the $1 \%$ concentration level metric.

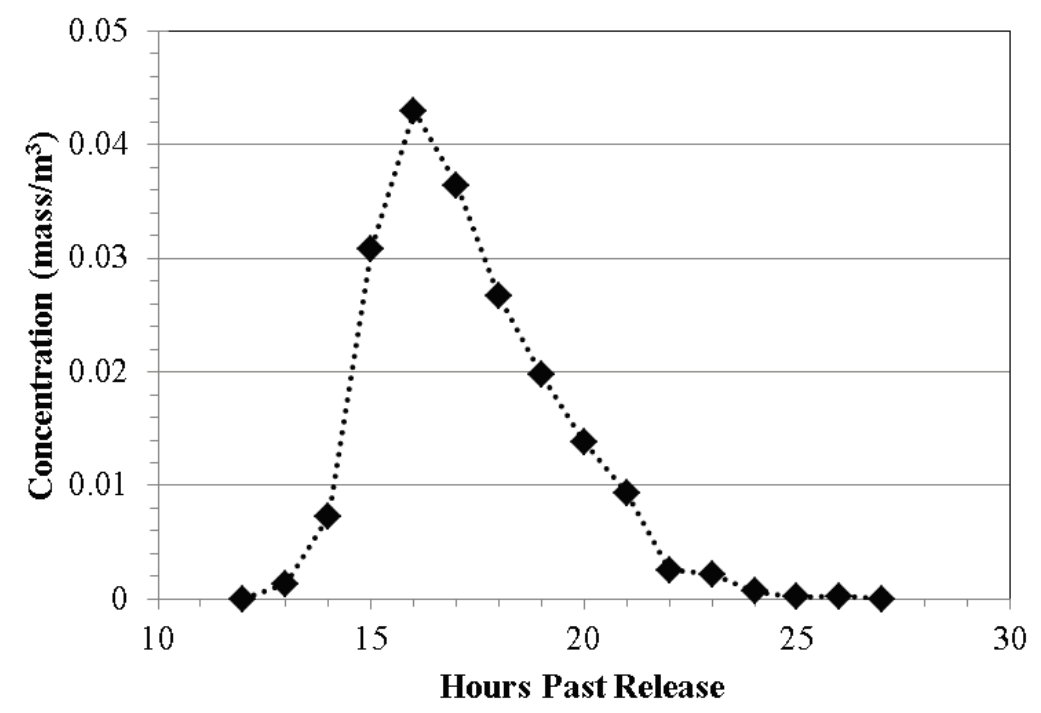

Figure 3.5 Example modeled plume time history at a distance of $250 \mathrm{~km}$ from the source.

\subsection{Uncertainty in Plume Concentrations}

Another consideration for optimizing the sampling duration is the magnitude of the concentration. Very low concentrations may require longer integration times in the sampler to achieve reliable counting statistics. The averages of maximum concentrations (maximum around the circle of a given distance) are provided in Figure 3.6 for a release of $10^{12}$ mass units of a nondecaying tracer. Concentrations for specific distances are given in a line in the plot, while the different lines represent different distances from the source to the sampler. The actual mass release is chosen arbitrarily, but the plot illustrates the increase in effective atmospheric dilutions at increasing distances. The vertical bars associated with each line show the central $90 \%$ of the 365 concentrations used in the average. These results show that the maximum plume concentration may vary by over an order of magnitude, in cases even approaching two orders of magnitude, even when the transport distance does not change. 


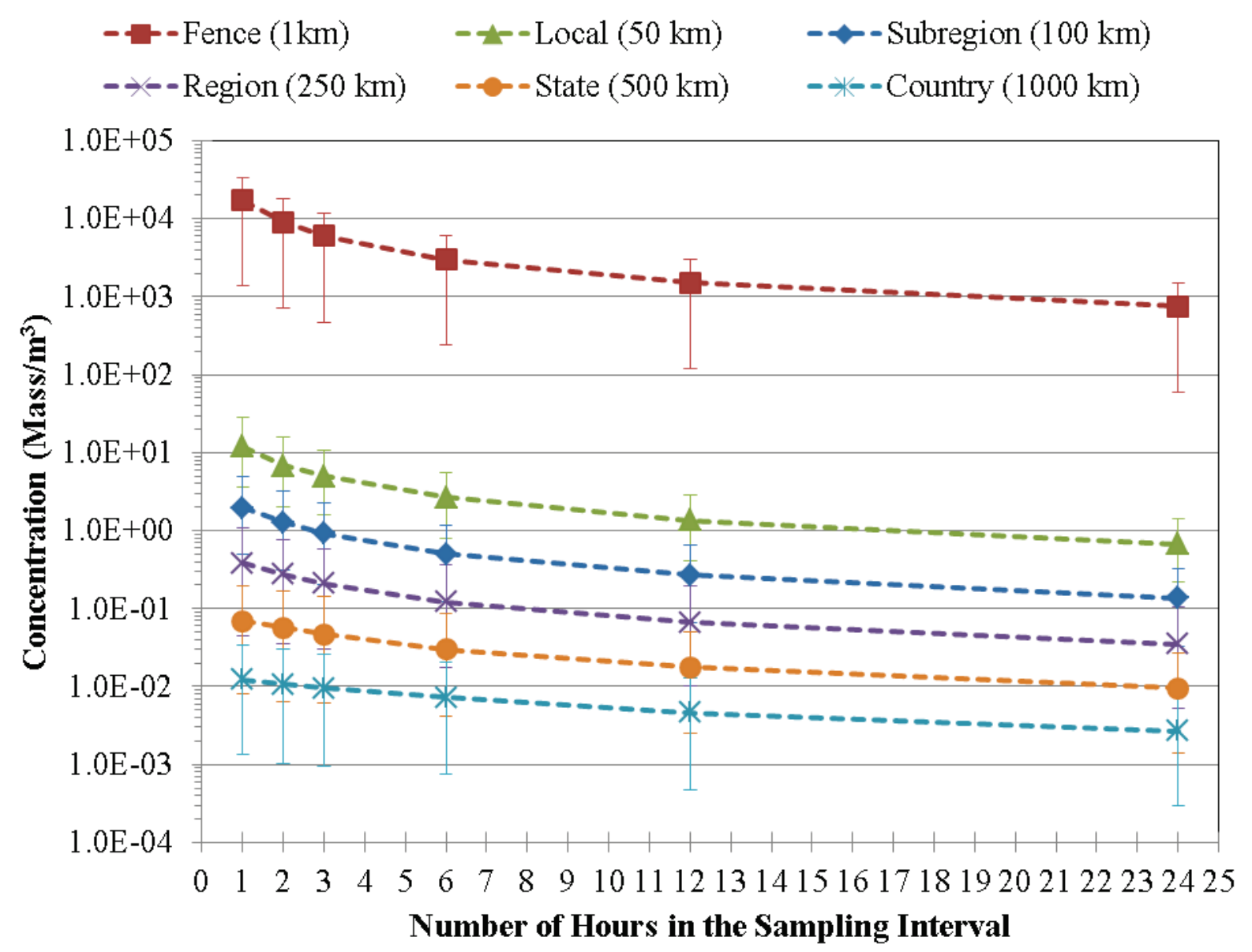

Figure 3.6 Average maximum concentrations and $90 \%$ concentration ranges as a function of distance and number of hours in the sampling interval for a 1-hour release of $10^{12}$ mass units.

\subsection{Discussion}

The results shown in Figure 3.6 illustrate the concentration inaccuracies that can result if the sample duration is long relative to the duration of the plume. For example, a short duration plume, say 3 hours, averaged over a 24 hour integration time will yield a concentration estimate that is too low by a factor of 8. If the contaminant is a relatively short lived isotope and the 3 hour plume arrives early in the 24 hour sample period, the derived concentration will be off by more than a factor of eight. In addition, for lowconcentration plumes, integrating a sample for longer than the actual plume transit increases the natural background isotopes, worsening the signal to noise ratio.

As noted in Section 1.0, most of the IMS radionuclide sampling locations are more than 1,000 km apart. Thus, optimization of the sample duration will depend in part on the distance from the release point to the sampler. If a goal were to capture essentially all of the plume in one time bin at least $50 \%$ of the time, 
then one would probably consider sample durations of 12 hours (as shown in the $500 \mathrm{~km}$ line on Figure 3.3), although the results in Figure 3.4 indicate that the majority (more than half) of mass in the plume will pass in 12 hours or less for about $95 \%$ of the plumes. If a goal were to have the major portion of the plume spread over 2 time bins, then one might consider sample durations of 6 to 8 hours. If however, one of the goals is to be able to distinguish samples collected near a release point from samples taken further away, then one would desire sample durations in the three hour range. These broad observations are offered without considering the necessary tradeoff between sample duration and the detection limit or uncertainty considerations imposed by sampler technology. 


\subsection{References}

CTBT. 1996. Text of the Comprehensive Nuclear-Test-Ban Treaty. United Nations Office for Disarmament Affairs (UNODA), Status of Multilateral Arms Regulation and Disarmament Agreements, CTBT. Accessed on September 20, 2012, at http://www.ctbto.org/the-treaty/treaty-text/

CTBTO. 2011. Ctbto Preparatory Commission Web Page. Accessed on September 24, 2011, at http://www.ctbto.org/

Draxler, RR, and GD Hess. 1998. "An Overview of the Hysplit_4 Modeling System of Trajectories, Dispersion, and Deposition." Aust. Meteor. Mag. 47:295-308.

EDAS. 2012. Downloadable North American (Nam Eta) Data Assimilation System 40 Km Meteorological Data Set Archive. Air Resources Laboratory, National Oceanic and Atmospheric Administration. Accessed on September 27, 2012, at ftp://arlftp.arlhq.noaa.gov/pub/archives/edas40/

GDAS. 2012. Downloadable Global Data Assimilation System Information Data Set Archive. Air Resources Laboratory, National Oceanic and Atmospheric Administration. Accessed on April 2, 2012, at ftp://arlftp.arlhq.noaa.gov/pub/archives/gdas1/

HYSPLIT. 2011. Air Resources Laboratory Hysplit Model. Accessed on October 3, 2011, at http://www.arl.noaa.gov/documents/Summaries/HYSPLIT_FINAL.pdf (last updated March 2011).

Thomas, CW, JK Soldat, WB Silker, and RW Perkins. 1977. Radioactive Fallout from Chinese Nuclear Weapons Test September 26, 1976., BNWL-2164, Battelle, Pacific Northwest Laboratories, Richland, Washington. 


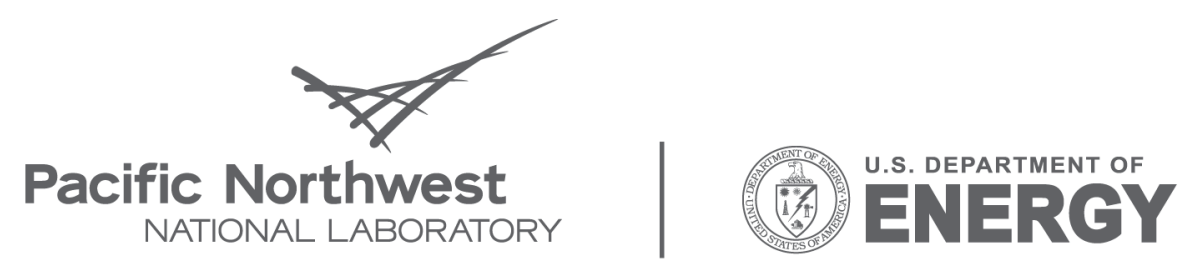

Proudly Operated by Battelle Since 1965

902 Battelle Boulevard

P.O. Box 999

Richland, WA 99352

1-888-375-PNNL (7665)

www.pnl.gov 